\title{
ETNOMATEMATIKA PADA PERMAINAN TRADISIONAL ENGKLEK DAN GASING KHAS KEBUDAYAAN SUNDA
}

\author{
Chatarina Febriyanti ${ }^{1}$, Rendi Prasetya ${ }^{2}$, Ari Irawan $^{3}$ \\ 1,2,3 Program Studi Informatika, Universitas Indraprasata PGRI Jakarta \\ Jl. Raya Tengah No. 80, Kel. Gedong, Kec. Pasar Rebo, Jakarta Timur 13760 \\ e-mail: ${ }^{1}$ chatarina022@gmail.com; ${ }^{2}$ prasetyarendi@gmail.com; ${ }^{3}$ ari_irawan@unindra.ac.id
}

\begin{abstract}
Abstrak
Penelitian ini bertujuan untuk mengungkapkan hal-hal apa saja yang terdapat unsur matematika pada kebudayaan sunda khususnya pada permainan tradisonal yang ada di Purwakarta. Dalam masyarakat sunda disadari atau tidak, banyak masyarakat yang menggunakan matematika dalam permainan anak. Metode dalam penelitian ini adalah survey eksplorasi dengan pendekatan kualitatif dimana instrument yang digunakan adalah lembar observasi, pedoman wawancara, studi literatur dan konsultasi dengan pakar etnomatematika. Hasil dari penelitian ini adalah dalam permainan anak khas kebudayaan sunda yaitu Engklek terdapat unsur geometri datar, yaitu persegi, persegi panjang dan setengah lingkaran dalam petakan yang digunakan dalam permainan. Selain itu terdapat pula unsur membilang pada permainannya. Sedangkan untuk gasing terdapat unsur matematika berupa tabung yang bentuk permainanya seperti tabung. Dalam proses permainannya terdapat unsur pendidikan karakter berupa kebersamaan, kejujuran, sportivitas dan lain-lain.
\end{abstract}

Kata kunci : Etnomatematika, Sunda, Gasing, Tapak gunung

\section{ETHNOMATHEMATICS OF TRADITIONAL GAMES “ENGKLEK AND GASING” OF SUNDA CULTURE}

\begin{abstract}
This study aims to reveal what things there are elements of mathematics in Sundanese culture, especially in traditional games that exist in Purwakarta. In the Sundanese society it is recognized or not, many people use mathematics in children's games. The method in this research is exploratory survey with qualitative approach where instrument used is observation sheet, interview guide, litertaur study and consultation with expert of etnomatematics. The result of this research is in children's game typical of Sundanese culture that is a flat geometry, ie square, rectangle and semicircle in the game used in game. In addition there are also elements to count on the game. Sedankan for gasing there are mathematical usnur in the form of tubes that form the game like a tube. In the process of game there are elements of character education in the form of togetherness, honesty, sportsmanship and others.
\end{abstract}

Keywords : etnomatematics, Sundanese, gasing, tread mount

\section{Pendahuluan}

Tidak kita pungkiri, adanya kemajuan teknologi di era globalisasi secara langsung atau tidak langsung telah menggeser kebiasaan anak-anak dalam berperilaku. Baik dalam permainan, perilaku, gaya hidup maupun cara belajar. Anak-anak sudah meninggalkan permainan tradisonal yang dianggap kuno dan tidak menyenangkan lagi, padahal banyak manfaat yang bisa didapat dari ragam permainan tradisional.

Etnomatematika sendiri merupakan unsur budaya yang yang terdapat pembelajaran matematika [1]. Adakalanya matematika sulit dipahami oleh siswa karena proses belajar matematika cenderung formal dan kaku serta kurang menyenangkan. Disamping itu pemahaman tentang nilai-nilai dalam pembelajaran matematika yang disampaikan para guru belum menyentuh keseluruh aspek yang mungkin. Ada indikasi terdapat hubungan yang saling asing Antara materi matematika di sekolah dengan kehidupan keseharian 
siswa setempat. Siswa sekolah dasar yang berada fase kongkrit dan masa bermain membutuhkan suatu sentuhan materi matematika yang nyata dan sering dijumpainya serta menyenangkan. Maka unsur-unsur matematika yang ada dalam budaya masyarakat perlu untuk dikaji lebih lanjut untuk menumbuhkan rasa cinta terhadap budaya peninggalan nenek moyang. Dalam hal ini kajian yang dilakukan berupa eksplorasi etnomatematika yang terdapat dalam permainan anak. Berdasarkan hal tersebut, maka peneliti melakukan kajian tentang eksplorasi etnomatematika pada permainan tradisional anak di kabupaten Purwakarta [2].

They are difficult to solve the math problem in the form of the mathematical project because during this time students tend to be taught practical formulas that will be used to answers the exam questions [3]. Hal ini membuat siswa telalu banyak berfikir praktis bagaimana rumus yang telah diajarkan hanya diimplementasikan untuk menjawab soal-soal. Dalam proses berpikir siswa dengan menggunakan etnomatematika, siswa akan di berikan keleluasan untuk mengidentifikasi bagaimana unsur matematika terdapat dalam budaya masyarakat kita.

\section{Metode Penelitian}

Penelitian ini dilaksanakan kabupaten Purwakarta. Penelitian ini dilaksanakan mulai Januari Desember 2017, dimana yang menjadi obyek penelitian pada penelitian ini adalah sebuah acara yang diadakan setiap pekan bernama "kaulinan barudak" yang terdapat di kabupaten Purwakarta. Metode yang digunakan dalam penelitian ini dalah survey ekslporatif. This research uses the ethnographic approach as a research approach [3]. Instrumen yang digunakan berupa panduan observasi dan wawancara yang dilakukan kepada panitia acara kaulinan barudak, dinas pariwisata kabupaten Purwakarta dan pihak sekolah masih menggunakan adat dan kebudayaan sunda sebagai pengayaan infomasi.

\section{Hasil dan Pembahasan}

Anak memiliki karakteristik tertentu yang khas dan tidak sama dengan orang dewasa, mereka selalu aktif, dinamis, antusias dan ingin tahu terhadap apa yang dilihat, didengar, dirasakan, mereka seolah-olah tak pernah berhenti bereksplorasi dan belajar [4]. Anak merupakan jiwa-jiwa yang haus akan pengetahuan maka diberdayakan dalam sebuah permainan tradisional yang memang tidak hanya mengasah motif kasar dan halus akan tetapi bagaimana pendidikan karakter di optimalkan. Matematika sesungguhnya telah digunakan oleh setiap orang dalam kehidupannya. Betapapun primitifnya suatu masyarakat, matematika adalah bagian dari kebudayaannya [5].

Berdasarkan hasil analisis, maka bentuk etnomatematika masyarakat Purwakarta berupa berbagai aktifitas matematika yang dimiliki atau berkembang dalam permainan anak tradisional di acara kaulinan barudak kabupaten Purwakarta, meliputi konsep-konsep matematika dalam engklek dan gangsing. Etnomatematika merupakan suatu integrasi budaya dan matematika maka dari itu, guru yang ada di sekolah berupaya untuk mengajarkan matematika dengan budaya lokal setempat sehingga sangat mudah untuk siswa merasakan keberadaan matematika dalam kehidupan sehari-hari [6].

Etnomatematik menggambarkan semua hal yang membentuk identitas budaya suatu kelompok, yaitu bahasa, kode, nilai-nilai, jargon, keyakinan, makanan dan pakaian, kebiasaan, dan sifat-sifat fisik. Sedangkan matematika mencakup pandangan yang luas mengenai aritmetika, mengurutkan, mengklasifikasikan, menyimpulkan, dan modeling [7]. Kabupaten Purwakarta sangat konsisten dalam menghidupkan budaya sunda. Implementasinya sangat banyak, baik dalam pemerintahan, sekolah maupun permainan anak-anak. Setiap hari minggu, diadakan festival permainan anak yang bisa dilihat untuk umum. Pada hari sabtunya terdapat acara di alun-alun sri baduga berupa air mancur menari. Pada permainan anak, peneliti memperhatikan terdapat permainan yang memiliki unsur matematika yaitu sebuah permainan bernama tapak gunung (Engklek), dan gasing.

Tapak gunung atau sering juga disebut engklek adalah salah satu permainan tradisional yang terkenal di Indonesia, khususnya bagi masyarakat pedesaan. Engklek dapat kita jumpai di berbagai wilayah di Indonesia, seperti di Sumatera, Jawa, Bali, Kalimantan dan Sulawesi. Engklek memiliki nama yang berbeda-beda di setiap daerah. Khusus di Jawa permainan ini disebut Engklek, dan pada umumnya permainan ini banyak dimainkan oleh kaum perempuan. Di beberapa tempat disebut pula dengan nama permainan taplak, terbagi atas taplak meja dan taplak gunung. Ada dugaan bahwa permainan ini berasal dari "Zondag-Mandag” berlatar belakang tentang cerita perebutan sawah yang berasal dari negeri kincir angin yaitu Belanda, versi mereka zondag mandag pun diartikan sebagai Sunday Monday, yang telah 
menyebar ke Nusantara pada zaman kolonial Belanda. Namun ada seorang sejarawan yang mendeskripsikan bahwa permainan engklek bukanlah berasal dari Belanda, menurut Dr. Smupuck Hur Gronje, permainan engklek adalah sebuah permainan yang berasal dari Hindustan yang kemudian diperkenalkan di Indonesia. Itulah yang menyebabkan engklek terkenal di kalangan masyarakat Indonesia, meskipun setiap provinsi nya memberikan nama yang berbeda-beda.

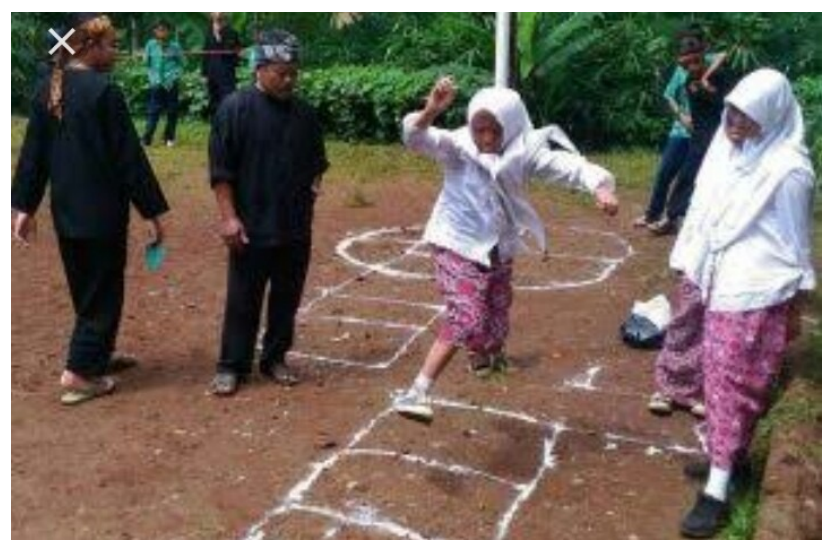

Gambar 1. Permainan Tapak Gunung/Engklek

Manfaat Permainan Engklek: 1) Meningkatkan kemampuan fisik setiap pemainnya, melalui lompat melompat yang dilakukan, jadi dapat melancarkan peredaran darah. 2) Melatih keseimbangan badan, karena engklek hanya dimainkan oleh satu kaki. 3) Mengasah kemampuan bersosialisasi seseorang dengan orang lain serta memberikan nilai kebersamaan pada saat permainan dilaksanakan. 3) Memiliki kemampuan untuk berusaha menaati peraturan yang telah menjadi kesepakatan antar para pemainnya. 4) Menyongsong kecerdasan logika pada pemainnya, karena dalam permainan ini seseorang juga diajarkan berlatih berhitung dan tahap-tahap yang harus dilewatinya. 5) Menjadi lebih kreatif, karena jenis permainan tradisional pada umumnya dibuat langsung oleh para pemainnya langsung, menggunakan barang-barang yang ada di sekitar lingkungannya, kemudian diolah menjadi suatu permainan yang menyenangkan. Hal inilah yang membuat mereka menjadi lebih kreatif dalam menghasilkan permainan. Adapun aspek matematika dalam permainan ini adalah sebagai berikut: 1) Pengenalan Angka-angka dan berlatih berhitung. 2) Pengenalan bangun datar yang terdapat pada lumpak atau petak-petak engklek atau rumah engklek di atas tanah. Bangun datar yang digunakan berbeda-beda di setiap daerah, ada yang berupa perpaduan antara segitiga dan persegi panjang. Ada juga yang merupakan perpaduan Antara setengah lingkaran, persegi dan persegi panjang. Tidak ada standar yang baku dalam pembuatan engklek ini, misalnya berupa ukuran bidang datar yang digunakan atau juga standar macam-macam bidang datar yang digunakan. 3) Konsep probabilitas dalam proses penggunaan guncu/gacuk/imat untuk menentukan "salah/benar" atau "mati/lanjut". Engklek merupakan permainan yang didalamnya terdapat unsur geometri datar dimana jika ditelah lebih lanjut bisa diterapkan juga dalam pembelajaran matematika tentang geometri datar [8].

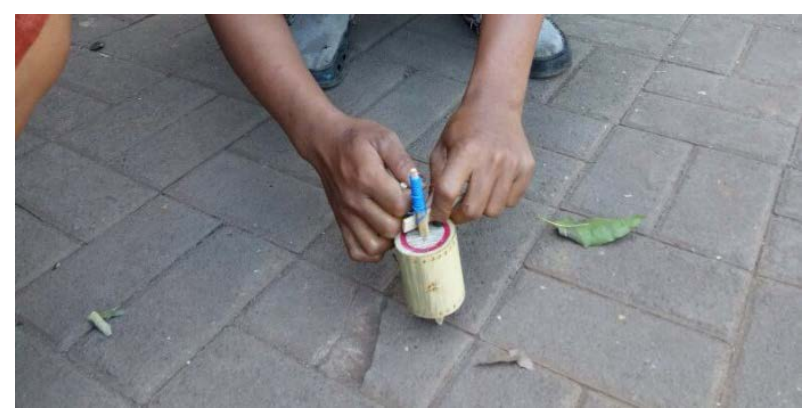

Gambar 2. Permainan gasing 
Permainan lainya yaitu permainan gasing yang biasanya dimainkan oleh anak laki-laki. Permainan paling popular dikalangan anak-anak ini, juga terdapat di Purwakarta. Terbuat dari bambu berbentuk tabung dengan tali untuk menariknya sehingga dapat berputar. Jika diperhatikan terdapat unsur etnomatematika di dalam permainan ini, yaitu bangun ruang berupa tabung. Anak-anak dilatih ketrampilannya untuk membuat gasing bisa berputar dengan cepat dan lama. Dalam festival bocah, gasing ini juga dilombakan untuk mendapatkan pemenang dalam hal durasi lamanya berputar. Sama halnya dengan dampu, pembuatan gangsing juga belum terdapat standart yang baku. Pemilihan bahan berupa bambu didapat oleh pengrajin tanpa mengukur besaran diameternya. Setelah dihaluskan, bambu diberi lubang tempat keluar suara pada saat gangsing diputar. Tidak jarang pengrajin harus mengubah bentuk gangsing agar lebih ramping agar dapat berputar lama dan berbunyi nyaring.

Penggunaan sumber daya alam sebagai media pembelajaran diharapkan dapat membuat siswa lebih memahami materi yang disampaikan karena proses penyampaian yang tidak monoton, membuat siswa memahami dan lebih mencintai keanekaragaman hayati yang ada dilingkungannya, serta melestarikan permainan-permainan sederhana yang ada di masyarakat [9]. Segala bentuk budaya yang berkaitan dengan matematika dapat digunakan sebagai bahan pembelajaran. Khususnya pada permainan engklek dan gasing yang banyak terdapat unsur geometri. Dalam permainan engklek juga banyak terdapat latihan berhitung.

Ethnomathematics is not only at the implicit level or just a composition of ideas, but also it was explicitly practiced in reality, presented and still being presented by different cultural groups [10]. Ini menyatakan bahwa Ethnomatematika tidak hanya pada tingkat implisit atau hanya komposisi gagasan, tapi juga secara eksplisit dipraktekkan dalam kenyataan, dipresentasikan dan masih dipresentasikan oleh kelompok budaya yang berbeda. Perlu adanya pengungakapan yang lebih mendalam dalam etnomatematika permainan khas sunda yang masih begitu banyak.

Ethnomathematics not only math but also explore the cultural values that existed inside [3], artinya dalam etnomatematika bukan saja hanya memahami bahwa matematika akan tetapi lebih dalam lagi bagaimana nilai-nilai budaya yang ada dalam warisan leluhur nenek moyang dapat bermanfaat dan relevan dengan kehidupan jaman sekarang. Menjadi penting bahwa matematika yang terdapat dalam unsur budaya dapat dijadikan pegangan bagi para pendidik matematika untuk dapat memanfaatkan permainan lokal yang masih kental budaya untuk dijadikan bahan pembelajaran siswa. Selain itu menanamkan unsur pendidikan karakter berupa kejujuran, kebersamaan, dan sportivitas yang tinggi dalam melakukan permainan tradisional.

\section{Kesimpulan}

Berdasarakan uraian tersebut maka dapat disimpulkan bahwa dalam permainan tradisional khas kebudayaan Sunda yaitu engklek dan gasing terdapat unsur matematikanya yaitu berupa geometri datar untuk engklek dan geometri ruang untuk gasing. Permainan engklek juga terdapat unsur membilang dari 1-9 pada tiap-tiap petakan yang dibuat. Permainan tradisional ini juga dapat melatih karakter siswa baik itu kejujuran, mengantri permainan, kebersamaan dan sportivitas. Dalam permainan juga melatih motorik halus dan motorik kasar siswa yang mainkanya berupa kesimbangan dan lainnya.

\section{Ucapan Terimakasih}

Terimaksih kami ucapkan kepada 1) DRPM Kemenristek Dikti, 2) Kopertis Wilayah III, 3) Pemerintah Kab Purwakarta yaitu dinas pendidikan dan dinas pariwisata, 4) Prof. Turmudi (Univ Pendidikan Indonesia), 4) Universitas Indraprasta PGRI.. Pihak-pihak yang telah membantu dalam proses penelitian kami sehinga dapat kami selesaikan dengan baik.

\section{Daftar Pustaka}

[1] A. Irawan and G. Kencanawaty, “Implementasi pembelajaran matematika realistik berbasis etnomatematika,” J. Medives, vol. 1, no. 2, pp. 74-81, 2017.

[2] N. Rusliah, "Pendekatan Etnomatematika dalam Permainan Tradisional Anak di Wilayah Kerapatan Adat Koto Tengah Kota Sungai Penuh Propinsi Jambi,” 2016, pp. 2-5.

[3] Risdiyanti and R. C. I. Prahmana, “Ethnomathematics: Exploration in Javanese Culture,” in Journal of Physics: Conference Series, 2017, pp. 1-6. 
[4] E. J. A. Luckrista and D. Komalasari, "Pengaruh permainan kayu malele terhadap kemampuan mengenal konsep ukuran anak,” pp. 1-6.

[5] Sudirman, Rosyadi, and W. D. Lestari, "Penggunaan etnomatematika pada karya seni batik Indramayu dalam pembelajaran geometri transformasi,” Pedagogy, vol. 2, no. 1, pp. 74-85, 2017.

[6] G. Kencanawaty and A. Irawan, "Penerapan etnomatematika dalam pembelajaran matematika di sekolah berbasis budaya,” J. Ekuivalen, vol. 27, no. 2, pp. 169-175, 2017.

[7] Marsigit, "Pembelajaran matematika dalam perspektif kekinian,” Math Didact. J. Pendidik. Mat., vol. 2, no. 3, pp. 132-141, 2016.

[8] A. Irawan, "Penggunaan ethnomatematika engklek dalam pembelajaran matematika,” J. MathEducation Nusant., vol. 1, no. 1, pp. 46-51, 2018.

[9] R. M. Hariastuti, "Permainan tebak-tebakan buah manggis: sebuah inovasi pembelajaran matematika berbasis etnomatematika,” J. Mat. dan Pendidik. Mat., vol. 2, no. 1, pp. 25-35, 2017.

[10] O. A. Cimen, “Discussing Ethnomathematics: Is Mathematics Culturally Dependent?,” Procedia - Soc. Behav. Sci., vol. 152, pp. 523-528, 2014. 
